\title{
A Study on Phenomenon of "Bad Money Drives out Good” in Jinlin Province Labor Market from Perspective of Complex Man
}

\author{
Houceng \\ Department of Business Management \\ Jilin Business and Technology College \\ Jilin Province, Changchun \\ 770696641@qq.com
}

\begin{abstract}
Starting from the existing problems of labor market in Jinlin province, this thesis describes the current situation of labor market in Jinlin province and puts forward the severe phenomenon of "bad money drives out good" in the labor market of Jinlin province. The limitations of "economic man" assumption for explaining the phenomenon of "bad money drives out good" in the labor market of Jinlin province are analyzed in detail so as to further propose that the root of "bad money drives out good" in labor market should be excavated from the perspective of "complex man"; under the guidance of this thought, the functional mechanism of "bad money drives out good" in the labor market of Jinlin province is discussed deeply and the solutions are analyzed through the construction of mathematical model.
\end{abstract}

Keywords_Labor Market; “Complex Man” Assumption; Bad Money Drives out Good

\section{CuRREnT Situation AND EXISTING Problems OF JinLiN PROVINCE LABOR MARKET}

Since the reform and opening-up, Jinlin province has gained achievements in employment with gradually perfect social security system. However, the labor market of Jinlin province has many problems with wide scope that are urgent to be solved.

\section{A. Coexistence of High Unemployment Rate and Low Labor Participation Rate}

From the angle of unemployment rate, the unemployment problem of urban residents in Jinlin province is severe. It is shown in the statistical data of Jinlin province in 2010 that the entire unemployment rate has reached $8.01 \%$, among which the urban unemployment rate is $9.57 \%$ and rural rate is 5.28. Such unemployment rate is much higher than the unemployment warning line of $7 \%$. By gender, the unemployment rate of female in Jinlin province is higher than male; by age, the unemployment rate tends to decline along with age growth and the unemployment rate of female below 49 years old is higher than male; however, the unemployment rate of male is higher than female between 50 to 54 years old and afterwards, the unemployment rate of female tends to rise year by year and is always higher than male.

\section{B. Homodromous Variation of Education Level and Unemployment Rate}

Generally speaking, the higher the education level, the smaller the possibility to be unemployed. This is because the ability to compete for a position will be stronger along with the raise of education level[1]. However, the unemployment rate and education level in labor market of Jinlin province tend to have the synthetic correlation instead of such reverse correlation. In Jinlin province, the laborers with extremely high education level, such as doctoral candidate, have preferable job opportunities; however, besides these people, the people with the lowest and highest education level are not the labor force with the highest unemployment rate in Jinlin province, instead it is the labor force with moderate education level.

\section{Interdependence of Household Registration System}

The Chinese household registration system has been a long-standing problem with different treatments on urban household registration and non urban household registration. Hence, there is tremendous and even abnormal difference on the working behaviors of laborers with different household registrations. When applying for a post, the laborers with non rural household registration has higher metal position as well as higher requirements on position, wage and treatment and geographic position; due to the instinctive superiority, the laborers with non rural household registration find it difficult to find jobs after unemployment. The statistics show that the unemployment rate of laborers with non rural household registration is more than three times of the laborers with rural household registration.

\section{Regional Difference}

The problems of the labor market in Jinlin province are different in different regions. For example, the unemployment phenomenon in Baicheng city and Tonghua city is milder and that in other regions is more severe with the highest unemployment rate in Liaoyuan city where the unemployment rate reached $10.27 \%$ once. For Jinlin province, all the labor market problems contain a more severe economic problem that is the excellent labor force with more value creativity do not 
jobs and the imperfect labor force with few value creativity occupy the posts, which is a typical economic phenomenon of "bad money drives out good" that should be analyzed from the deeper level of economics.

\section{LIMITED EXPLANATORY ABILITY OF “ECONOMIC MAN” ASSUMPTION ON PHENOMENON OF "BAD MONEY DRIVES OUT GOOD” IN JINLIN PROVINCE LABOR MARKET}

\section{A. Information Asymmetry as Objective Condition of "Bad Money Drives out Good"}

There are three ways for the employers to acquire the information of a laborer: searching, experience and credibility. Firstly, the employer should acquire the external information of a laborer, including knowledge, experience, technical ability and physical condition through searching, which can be determined by the sense organ of the employer and thus the acquired information is explicit and reliable; then the employer will experience the laborer through actual behavior; if the information is inconsistent with expectation, the repeated purchase behavior of the employer for this laborer will not be formed, which will not cause larger damage to the production and management of the employer; the employers acquire the information of the laborer through credibility that is to acquire the relevant information through the credibility of laborer[2] ; however, these information is always the information employer should know but fail to acquire and should be provided by the laborer, such as the labor capacity, value and loyalty index of the laborer, which can't be acquired through searching or experience and can't be verified within certain period or be verified at extremely high expense. At this time, the employer can only affirm the information through the credibility of the laborer and can't decide whether the information confirms to reality, which is the origin of information asymmetry in labor market.

\section{B. Limitations of"Economic Man"Assumption for Explaining Phenomenon of"Bad Money Drives out Good"in Labor Market}

The "economic man" hypothesis of Adam Smith fails to correspond with reality in many cases and the reality is that the severe phenomenon of "bad money drives out good" appears in labor market of Jinlin province. The mediocre laborer may package himself (such as obtaining certificates without use value) and even provide false information and acquire the job at the wage level lower than excellent talents; driven by interests, the other mediocre laborers may imitate him and the phenomenon of "bad money drives out good" will come into play; the phenomenon of "embellishing resume" in labor market continues despite repeated prohibition and the normal market operational mechanism is disturbed. Such behavior of mediocre laborer can't simply be explained through "economic man" theory because the precondition for the mediocre laborer to obtain the salary higher than his practical level is the extremely complicated analysis of human nature; the employer employs the laborer with lower ability and lower cost than excellent laborer owing to the self-interest because the largest self-interest is the existence of the enterprise.
Through the above analysis, it can be seen that the "economic man" assumption fails to make a reasonable explanation on the phenomenon of "bad money drives out good” in labor market and thus the humanity hypothesis that is in consistent with the actual situation should be applied to analyze the complex phenomenon in the labor market of Jinlin province.

\section{AnAlysis on Functional MEChanism of "BAD MONEy DRIVES OUT GOOD” IN JINLIN PROVINCE LABOR MARKET}

\section{A. "Complex Man" - Humanity Foundation of "Bad Money Drives out Good" in Labor Market}

1) The pursuit for material benefits is the soil for problems in Jinlin province labor market.

The material interest is what the employers and laborers pursue for. The laborers have advantages in information during the job hunting link and the employer is willing to take risks due to the mercenary nature in order to gain more economic interests. The laborers will make the best of their information advantage to adulterate when the employer strives to know their information through credibility and even get the position through deception means[3].

For the common employers, they are incapable of acquiring the deep quality of the laborer after obtaining the slight information through searching or experience. At this time, the mercenary nature comes into play and the employer will assume that the laborers are equally excellent (testified by the resume) after reading the elaborate resume and then select the laborer at lower cost so as to obtain the same output with the least money.

\section{B. The "exploratory behavior" of supplier and demander is} the boosting for problems in labor market.

Due to the laborer and employer's pursuit of material interests, the survival soil for the "bad money drives out good" problem in labor market appears and they all obtain the "interests" they pursue for in this link. However, the employer is not simply the seeker of interests and he is aware of the damage the shoddy laborer will bring to its development; meanwhile, the laborer also take a tremendous risk while acquiring extravagant profits through falsification; however, the existence of such gambling is due to the complexity of people.

Both the employer and laborer are tentative when making decision. Due to enterprise competence, short-sighted behavior and vanity, the employer will try to employ the under-grade laborer with "top grade external packing", offering the realistic possibility for the speculative behavior and driving force for shoddy laborer. The shoddy laborer aims to acquire the employer's acceptance level on shoddy behavior through exploration and they are willing to take a tremendous risk duo to the enormous earnings[4]; the laborers are successful because they grasp the vain employment psychology and short-sighted behavior of the employers and use the luxurious external packing and the so-called "high resume" to attract the employers; in fact, the shoddy laborer will bring enormous 
damage to the employer; however, enormous benefits will be brought to the laborer after successful trade.

In this way, it is possible for the existence and repeated emergence of inferior food owing to the economic interest and exploratory behavior.

\section{Functional Mechanism Model of "Bad Money Drives out Good" in Labor Market}

All the links of recruitment include many conflicts of interests and the carrier for each link is "people"; due to the particularity of people and the special meaning of job for people, the discussion on labor market problems should not be restricted to the superficial supervision; instead, its inherent functional mechanism should be excavated from deep level so as to find the reasons for problems in labor market fundamentally and eliminate them, which is the fundamental solution for the impending problems in the labor market of Jinlin province.

Actually, if most people are risk lovers, then adulteration will be the selection of most people. However, people are complicated and are not simple pursuers for economic interests; therefore, they are more willing to be risk evaders under normal circumstance. As the risk evaders, they adulterate because life is filled with uncertainty and people need to make decisions and select when unable to be aware of the results; moreover, adulteration is the "rough" behavior under the conditions of uncertainty[5].

Assume that $\mathrm{Li}$ is a risk evader with inferior moral responsibility consciousness and his ability is $\mathrm{M}$, he will gain high profits through taking the high risk when he is arrested if his ability is exaggerated into $2 \mathrm{M}$ and the profits can be $\mathrm{n}$ times of the profits for his own ability. If his ability is exaggerated for 1 unit without being found out, his earning will be R Yuan; the fine after being found out will be $f$ Yuan and the probability for being found out is p. The detected false ability can be represented by $\mathrm{X}$ and the undetected one by $\mathrm{Y}$. In the following table, the vertical coordinate is used to denote the earnings of Li for Y ability and the horizontal coordinate is used to denote the earnings of Li for X ability. When Li does not exaggerate his ability $M$, his wealth is $M$ Yuan from both the vertical and horizontal coordinates that is point $\mathrm{A}$. If $\mathrm{Li}$ wants to exaggerate his ability for one unit, his wealth will add $\mathrm{R}$ Yuan and become $(\mathrm{M}+\mathrm{R})$ Yuan when he is not found out; if he is found out, his wealth will reduce $\mathrm{f}$ Yuan and become (Mf) Yuan that is point B in the coordinate system. In this way, the line segment determined by point $\mathrm{A}$ and $\mathrm{B}$ is the budget constraint line of $\mathrm{Li}$ and its slope is $-\mathrm{R} / \mathrm{f}$. The horizontal expansion of this line should not pass point A; if passing, it means that $\mathrm{Li}$ will gain more earnings that will be more than M Yuan when his false abilities are found out, which is impossible; the vertical extension can intersect with the vertical axis, meaning that his wealth will turn into $M(1+R)$ when his false abilities are sold out without being found out.

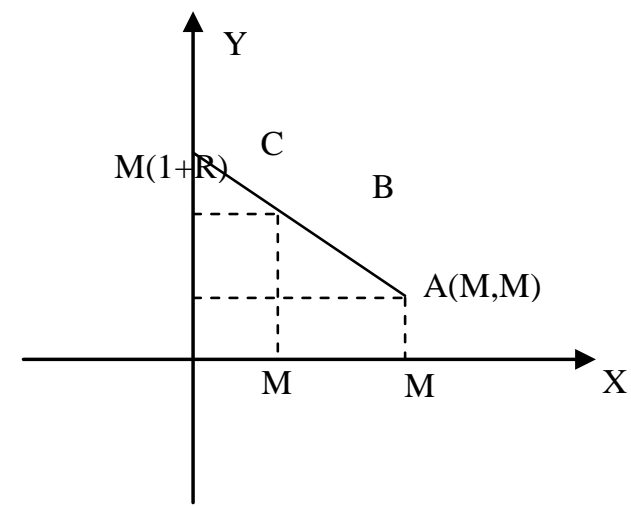

Fig. 1. Earning of adulterate

It can be known from the above analysis that when the earning of $\mathrm{Li}$ is within the budget constraint line a, $\mathrm{Li}$ tends to adulterate because his earnings will be much more than the losses when being found out and he thinks it deserving to take the risk of being found out. That is to say, if losses for being found out is greater than or equal to earnings for not being found out, Li will not adulterate. The formula for the critical point of Li's adulteration is as follows:

$$
\mathrm{P} * \mathrm{f}=(1-\mathrm{p}) * \mathrm{R},
$$

It is obtained through transposition and combining like terms

$$
\mathrm{f}=[(1-\mathrm{p}) / \mathrm{p}] * \mathrm{R}
$$

It is known that when the penal sum is less than or equal to $[(1-p) / p] * R$, Li will adulterate.

\section{CONCLUSION}

If most of laborers make decisions like Li (actually it is), it means that there are many shoddy behaviors in the labor market and the really excellent laborers who abide by market disciplines will be in the disadvantageous position. Firstly, the excellent laborers have paid a high cost to improve their abilities and their expectant wage rate will be higher, which may provoke dissatisfaction of employer intuitively; secondly, the employer can not know who is the excellent talent and they would rather pay a lower price to purchase the "defined shoddy talent" than pay a higher price to purchase the "possible excellent talent" under the condition of information asymmetry because the consumer does not want to bear the risk of high price. Under the double acting force, the excellent laborers will exit the labor market and even join in the shoddy group due to the mental imbalance. Under such circumstance, the market will be flooded with the shoddy behaviors and the employers will have no confidence on the actually excellent talents so that they are willing to use the shoddy people with general ability. Finally, the excellent talents will exit the market gradually and the shoddy people will occupy the posts so that the classical phenomenon of "bad money drives out good" in economics will appear, causing the labor market in Jinlin province to be disordered. 


\section{REFERENCES}

[1] Thomas Mark, Vallée Luc. Labour Market Segmentation

[2] in Cameroonian Manufacturing[J]. The Journal of Development Studies, 1996;32(6):876-898.

[3] Fontaine F. Why are similar workers paid differently? The role of social network[J]. Journal of Economic Dynamics and Control,2008,12 (932) : $3960-3977$.

[4] Bramoullé Y,Saint-Paul G. Social networks and labor market transitions[J]. Labor Economics, 2010, 17( 1) : 188 - 195.

[5] Cox J C,Oaxaca R.L. Direct tests of the reservation wage property[J]. The Economic Journal, 1992, 102 (415) : 1423 - 1432. 